\title{
Digestibilidade (aparente) de sucedâneos do leite com bezerros
}

\section{Nutritive value of milk replacers through digestion trial with calves}

Júlio César ALVAREZ'; Carlos de Sousa LUCCI² ${ }^{2}$ Laércio MELOTTI
CORRESPONDENCE TO. Carlos de Sousa LucCi Departamento de Criaçáo de Ruminantes e Alimentaçáo Animal Faculdade de Medicina Veterinária - Zootecnia da USP Av. Duque de Caxias Norte, ne 225 13630-000 - Pirassununga - SP Brasil

1 - Mallinckrodt Medical do Brasil Ltda.

São Paulo - SP

2 - Faculdade de Medicina Veterinária e Zootecnia da USP - SP

\section{RESUMO}

Foram utilizados oito bezerros machos da raça Holandesa preta e branca (puros por cruzamento) em um ensaio de digestibilidade de quatro sucedâneos usados como únicas fontes alimentares e que variaram apenas quanto à natureza da proteína digestível empregada: A) $100 \%$ proveniente de proteína láctea; B) $20 \%$ de concentrado protéico de soja (CPS); C) $40 \%$ de CPS; e D) $60 \%$ de CPS. Os bezerros começaram a receber os sucedâneos a partir do $7^{\circ}$ dia de vida, e a partir do $21^{\circ}$ dia foram arreiados com bolsas coletoras de fezes e permaneceram em baias individuais por sete dias, considerados de adaptação. A partir do $28^{\circ}$ dia de experimento deu-se o período de coleta total de fezes com cinco dias de duração. Foram determinadas a digestibilidade da matéria seca, proteína bruta e ainda a absorção de matéria mineral. O delineamento estatístico foi inteiramente casualizado. Os coeficientes de digestibilidade aparente para matéria seca, proteína bruta e absorção da matéria mineral foram: A) 87,63, 85,39 e $69,97 \%$; B) $83,73,79,82$ e $52,54 \%$; C) $80,95,71,37$ e $65,35 \%$; D) $75,87,69,03$ e $42,86 \%$, respectivamente, os quais tiveram comportamento linear $(p<0,01),(p<0,05)$ e $(p<0,05)$, piorando à medida que CPS ingressou na dieta em maiores quantidades.

UNITERMOS: Proteína de soja; Bezerros; Substitutos do leite; Digestibilidade.

\section{INTRODUÇÃO}

$\mathrm{O}$ aproveitamento da proteína da soja quando empregada em sucedâneos do leite para bezerros, em substituição à proteína láctea, mereceu muitos estudos pela sua importância econômica.

Noller et al. ${ }^{14}$ (1956), trabalhando com bezerros, recebendo sucedâneos do leite à base de proteína de soja, encontraram coeficientes de digestibilidade (CD) de matéria seca (MS) e proteína bruta (PB) $33,8 \%$ e $-8,5 \%$ com 10 dias, $50,2 \%$ e $1,7 \%$ aos 18 dias, $76,3 \%$ e $56,3 \%$ aos 26 dias e $76,0 \%$ e $51,6 \%$ aos 34 dias, demonstrando a extrema variação do aproveitamento dessa proteína com o avançar de idade dos terneiros. Por outro lado. o tratamento ao qual a proteína de soja é submetida prova ser fator de extrema importância ao seu aproveitamento por bezerros recém-nascidos. Assim, Colvin; Ramsey ${ }^{4}$ (1968) estudaram sucedâneos contendo farelo de soja tostada como única fonte de proteína c observaram que seu valor nutritivo melhorava mediante pré-tratamento por 5 horas em solução ácida, pH 4,0 a $37^{\prime \prime} \mathrm{C}$, enquanto em outro experimento, contendo farelo de soja levemente tostado, os terneiros perderam peso. A junção dos dois fatores-idade dos bezerros e pré-tratamento da soja -, no que tange ao aproveitamento de sua proteína, parece ser do maior interesse. Nitsan et al. ${ }^{11,12}$ (1971, 1972) em uma série de experimentos avaliaram concentrado protéico de soja (60 e $65 \%$ de PB) e farelo de soja tostado (44 a $48 \%$ de $\mathrm{PB}$ ) como fontes protéicas $\mathrm{cm}$ sucedâneos do leite fornecidos para bezerros por 42 dias, a partir dos 3, 7, 10 ou 30 dias de vida. A digestibilidade dos componentes alimentares aumentou da primeira à oitava semana do início das dietas, e esse aumento foi maior naquelas à base de soja. A tostagem melhorou a digestibilidade de proteína de soja, de $72 \%$ (não tostada) para $79 \%$ (parcialmente tostada) e para $88 \%$ (tostada). Da mesma forma, preocupandose com pré-tratamento de soja, Pejic; Kay ${ }^{16}(1979)$ utlizaram 16 bezerros para medir a digestibilidade e o nível de retenção do nitrogênio de substitutos de leite à base de leite em pó desnatado (LD), soja integral (FSI) ou com sua gordura extraída (FSD). Os CD para MS e nitrogênio foram 0,92 e $(0,9) 1$ (LD), 0,85 e 0,85 (FSD) 0,86 e 0,85 (FSI) e 0,86 e 0,84 (farelo de soja integral, reduzido a $10 \%$ de gordura). A retenção de nitrogênio foi de $13,7 \mathrm{~g} / \mathrm{dia}$ no tratamento $\mathrm{I}, \mathrm{D})$ e aproximadamente $12,0 \mathrm{~g} /$ dia nos demais tratamentos.

Roy et al. ${ }^{\prime \prime}$ (1977), em experimentos com bezerros 
ALVAREZ, J.C.; LUCCI, C.S.; MELoTTI, L. Digestibilidade (aparente) de sucedâneos do leite com bezerros. Braz. J. vet. Res. anim. Sci. São Paulo, v.33, supl., p.281 285,1996

holandeses, compararam sucedâneos do leite em que a proteína láctea foi substituída pela do farelo de soja tratado por temperatura e alcalinização. Observaram que a digestibilidade da MS e da PB foi reduzida quando da utilização da proteína não láctca, havendo ainda redução da absorção de cinzas e cálcio.

Outros autores prosseguiram na linha de estudos sobre efeitos da modificação da soja antes de fornecê-la a bezerros, como Silva; Huber ${ }^{211}(1986)$, que, em experimento com animais alimentados com substituto do leite à base de proteína láctea, ou $66 \%$ de proteína de soja modificada, ou ainda $66 \%$ de farelo de soja aquecido, concluíram que a digestibilidade às 5 semanas de idade foi respectivamente: $90,8 \%, 87,2 \%$ e $85,3 \%$ para matéria orgânica (MO) e $82,6 \%, 72,1 \%$ e $64,1 \%$ para proteína.

Akinyele; Harshbarger ${ }^{1}$ (1983) $\mathrm{em}$ dois ensaios avaliaram a proteína de soja em substitutos de leite durante 12 semanas com 12 bezerros Holandeses divididos em 3 tratamentos (proteína láctea, concentrado protéico de soja ou farelo de soja integral). Os CD médios obtidos com 10 a 15 dias foram respectivamente $87,5 \%, 66,6 \%$ e $47,9 \%$ para $\mathrm{MS} ; 80,5 \%$, $57,2 \%$ e $28,5 \%$ para $\mathrm{PB}$; e $83,8 \%, 58,99 \%$ e $48,4 \%$ para matéria mineral (MM). Com 30 a 35 dias de idade os CD médios foram respectivamente: $92,0 \%, 70,0 \%$ e $71,0 \%$ para MS; $90,1 \%, 56,6 \%$ e $61,3 \%$ para PB; e $85,8 \%, 62,5 \%$ e $61,1 \%$ para MM. Os autores concluíram que o uso de substitutos à base de soja é mais bem aproveitado à medida que cresce a idade dos bezerros. Jenkins ${ }^{7}$ (1981) constatou que sucedâneos à base de soja não mostraram efeito na digestibilidade da MS, nitrogênio e lipídios. Campos; Huber ${ }^{3}$ (1983) submeteram bezerros Holandeses à alimentações com sucedâneos, substituindo até $50 \%$ de proteína láctea por concentrado protéico de soja, e encontraram para digestibilidade da MS, digestibilidade da $\mathrm{PB}$ e para a retençāo de nitrogênio valores inferiores para o tratamento com proteína de soja substituindo $50 \%$ da proteína láctea. Pimentel; Peixoto ${ }^{17}$ (1983) em ensaio com terneiros avaliaram a digestibilidade da proteína do leite "in natura" e um sucedâneo contendo extrato de soja. O CD da proteína do leite "in natura" foi 91,61\% c do sucedâneo, $78,8 \%$. Ezequiel et al. (1988) avaliaram a digestibilidade de três níveis de substituição do leite "in natura" (A); leite de soja $20 \%$ (B); 40\% (C); e $60 \%$ (D) em dezesseis terneiros que tiveram acesso a feno e a um concentrado comercial. Os CD encontrados respectivamente para MS foram: $82,57 \%$ e $84,13 \%$ (A); $85,03 \%$ e $83,43 \%$ (B); $77,91 \%$ e $76,81 \%$ (C); e $79,33 \%$ e $72,85 \%$ (D). Os autores sugeriram que durante o primeiro mês de vida o leite de soja pode substituir até $20 \%$ do leite "in natura", enquanto este percentual de substituição poderá chegar até $60 \%$ no segundo mês. Nornberg; Peixoto ${ }^{15}$ (1988) compararam a digestibilidade de proteína de um sucedâneo de leite contendo $20 \%$ de concentrado protéico de soja à do leite "in natura" e encontraram respectivamente: $77,93 \%$ e $91,61 \%$, para quatro dias de coleta em terneiros com aproximadamente duas semanas de vida.

O objetivo do presente trabalho foi avaliar o emprego do concentrado protéico de soja, produto comercialmente disponível no mercado, como fonte de proteína para sucedâneos de leite fornecidos a terneiros, em substituição à proteína láctea.

\section{MATERIAL E MÉTODO}

O presente ensaio foi realizado na Faculdade de Medicina Veterinária e Zootecnia da Universidade de São Paulo, no Campus de Pirassununga - SP, sendo utilizados oito bezerros machos de raça Holandesa preta e branca, puros por cruzamento.

Foram avaliados quatro sucedâneos do leite (únicos alimentos) e que variaram no que tange à natureza da proteína empregada: A - 100\% de proteína láctea (PL); B - 20\% de proteína originária de concentrado protéico de soja (CPS) e $80 \%$ de PL; C - 40\% de proteína procedente de CPS e $60 \%$ de PL; e D - 60\% de proteína procedente de CPS e $40 \%$ de PL. Os bezerros receberam colostro por 4 dias após nascimento $\mathrm{c}$, ainda nos dias $5^{0}$ e $6^{0}$ de vida, permaneceram em baias individuais recebendo leite de vaca "in natura" como único alimento.

A partir do $7^{\circ}$ dia os animais começaram a receber os sucedâneos, sendo dois bezerros alocados em cada um dos quatro tratamentos. No $21^{0}$ dia os terneiros foram arreiados com holsas para coleta, iniciando-se período de adaptação de sete dias; do $28^{\circ}$ ao $38^{\circ}$ dia de vida e, sempre durante pelo menos cinco dias consecutivos, foi feita a colheita do 
ALvareZ, J.C.; LUCCI, C.S.; MELOTTI, L. Digestibilidade (aparente) de sucedâneos do leite com bezerros. Braz. J. vet. Res. anim. Sci. Sāo Paulo, v.33, supl., p.281. $285,1996$.

total das fezes de cada animal. Os sucedâneos foram formulados de acordo com o National Research Council ${ }^{(1)}, 10$ $(1988,1982)$ e $\operatorname{Roy}^{18}(1980)$ e sua composição consta na Tab. 1.

Procurou-se ao início do trabalho, homogeneizar em $24,5 \%$ o teor de proteína digestível na matéria seca dos sucedâneos em todos os tratamentos.

Os sucedâneos foram diluídos na proporção de $100 \mathrm{~g}$ para cada $800 \mathrm{ml}$ de água aquecida a $37^{\circ} \mathrm{C}$, resultando em soluções com $12,5 \%$ de MS, oferecidas em baldes aos bezerros, duas vezes ao dia ( 7 h e 15 h), representando cada refeição $50 \%$ do total diário. A água foi ofertada "ad libitum", exceto nos 30) minutos anteriores e posteriores a cada alimentação, e o volume total de sucedâneo ministrado aos bezerros consta da Tab. 2.

Tabela 2

Oferta de sucedâneo reconstituído. Pirassununga - SP. 1989.

\begin{tabular}{c|c}
\hline Dias de vida & Volume (litros) \\
\hline $7-13$ & 5,04 \\
$14-20$ & 6,16 \\
$21-27$ & 7,08 \\
$28-33$ & 7,54 \\
\hline
\end{tabular}

O ensaio de digestibilidade seguiu a metodologia descrita por Melotti; Lucci ${ }^{8}$ (1969), executando-se um período préexperimental. No período principal ou de coleta, as fezes eram colhidas diariamente, pela manhã, durante o mínimo de cinco dias consecutivos. Do total dos excretos de cada bezerro tomou-se alíquota de $10 \%$ por peso, colocada em estufa a 65 $70^{\circ} \mathrm{C}$ por 72 horas para determinação da MS e, após moagem, foram realizadas análises bromatológicas conforme a Association of Official Analytical Chemists ${ }^{2}$ (1980). O delineamento estatístico foi $o$ inteiramente casualizado, segundo Gomes ${ }^{6}$ (1985).

Tabela 3

Composição bromatológica dos sucedâneos do leite em porcentagem na matéria seca (MS). Pirassununga - SP, 1989.

\begin{tabular}{l|c|c|c|c}
\hline \multirow{2}{*}{\multicolumn{1}{c|}{ Nutrientes }} & \multicolumn{4}{c}{ Tratamentos } \\
\cline { 2 - 5 } & $\mathrm{A}$ & $\mathrm{B}$ & $\mathrm{C}$ & $\mathrm{D}$ \\
& 0\% CPS & $20 \%$ CPS & $40 \%$ CPS & $60 \%$ CPS \\
\hline Umidade (\%) & 6,90 & 6,49 & 6,16 & 6,26 \\
Proteína Bruta (\%) & 23,86 & 24,53 & 25,38 & 26,44 \\
Fibra Bruta (\%) & 0,33 & 0,67 & 0,42 & 0,38 \\
Matéria Mineral (\%) & 10,52 & 10,02 & 11,65 & 10,03 \\
Cáicio (\%) & 1,72 & 1,75 & 1,79 & 1,75 \\
Fósforo (\%) & 0,82 & 0,83 & 0,91 & 0,84 \\
Extrato etéreo (\%) & 20,30 & 20,04 & 17,40 & 18,84 \\
\hline
\end{tabular}

\section{RESULTADOS E DISCUSSĀO}

Na Táb. 3 apresenta-se a composição bromatológica dos sucedâneos, analisados para umidade, proteína bruta (PB), matéria mineral (MM), cálcio, fósforo e extrato etéreo.

Observou-se aumento do teor de proteína bruta dos sucedâneos com o ingresso da proteína de soja; no sentido de equilibrar-se a ingestão de proteína digestível, em função de uma menor digestão das proteínas não-lácteas.

Os coeficientes de digestibilidade dos animais dos quatro tratamentos, bem como suas médias, são apresentados na Tab. 4.

A digestibilidade da MS dos sucedâneos diminuiu linearmente $(p<0,01)$ de 87,63 a $75,87 \%$ à medida que o concentrado protéico de soja passou a constituir de $0 \%$ a $60 \%$ de proteína digestível dos mesmos. Decréscimos de digestibilidade também foram encontrados por Noller et al. ${ }^{13,14}$ (1956); Jenkins ${ }^{7}$ (1981); Nitsan et al. ${ }^{11,12}$ (1972); Roy el al. ${ }^{19}$ (1977); Pejik; Kay ${ }^{16}$ (1979); Akinyele; Harshbarger ${ }^{1}$ (1983); Campos; Huber ${ }^{3}$ (1983) e Ezequiel et al. ${ }^{5}$ (1988). Entretanto, o grau de inclusão do concentrado protéico de soja afetou negativamente o CD da MS no presente trabalho, dado esse que está bem próximo dos valores observados por Pejic; Kayy ${ }^{16}$ (1979); Silva; Huber ${ }^{20}$ (1986); Akinyele; Harshbarger ${ }^{1}$ (1983) e Ezequiel et $a .^{5}$ (1988). Este decrécimo do $\mathrm{CD}$ de 87,63 a $75,87 \%$ não foi drástico como aquele detectado por Noller et al. ${ }^{14}$ (1956) com emprego de farelo de soja tostado, tendo o nível de $33,8 \%$ como o de maior participação da proteína de soja no sucedâneo.

Quanto à digestibilidade da proteína, foi para o tratamento A (sem CPS) igual a $85,39 \%$, e para o D (com $60 \%$ CPS) foi $69,03 \%$. A absorção da MM, que no tratamento A foi $69,97 \%$, alcançou $42,86 \%$ no tratamento $D$. Os valores encontrados para PB e MM também decresceram linearmente $(p<0,05)$, o que é concordante com as observações de Jenkins ${ }^{7}$ (1981); Akinycle; Harshbarger $^{1}$ (1983) e Silva; Huber ${ }^{20}$ (1986), tanto para o efeito em si, quanto para o grau em que tal redução ocorreu.

Noller et al. ${ }^{14}$ (1956) registraram digestibilidade de proteína láctea de $81,2 \%$ e de proteína de farelo de soja tostada de $-8,5 \%$, o que não ocorreu segundo dados de outros autores que trabalharam em concentrado protéico de soja (CPS), como Akinyele; Harshbarger' (1983), que encontraram $90,1 \%$ para o leite e $56,6 \%$ para CPS, e Campos; Huber $^{3}$ (1983), que relataram $85,2 \%$ para leite e $76,8 \%$ para CPS. Esses números sugerem um melhor aproveitamento do concentrado protéico de soja quando comparado ao farelo de soja, para bezerros pré-ruminantes, e ainda demonstram, em concordância com o presente trabalho, a menor digestão de 
AlvareZ, J.C.; LUCCI, C.S.; MELOTTI, L. Digestibilidade (aparente) de sucedâneos do leite com bezerros. Braz. J. vet. Res. anim. Sci. São Paulo, v.33, supl., p.281. $285,1996$.

Tabela 4

Coeficientes de digestibilidade da Matéria Seca (MS), Proteína Bruta (PB) e índices de absorção de Matéria Mineral (MM). Pirassununga - SP, 1989.

\begin{tabular}{c|c|c|c|c|c|c|c|c|c}
\hline \multicolumn{3}{c|}{ MS (\%) } & \multicolumn{3}{c|}{ PB (\%) } & \multicolumn{3}{c}{ MM (\%) } \\
\hline Trat. & Rep.1 & Rep.2 & Média & Rep.1 & Rep.2 & Média & Rep.1 & Rep.2 & Média \\
\hline A & 88,99 & 86,27 & 87,63 & 85,60 & 85,17 & 85,39 & 70,20 & 69,73 & 69,97 \\
B & 82,65 & 84,09 & 83,37 & 80,72 & 78,91 & 79,82 & 60,43 & 44,65 & 52,54 \\
C & 82,87 & 79,02 & 80,95 & 76,82 & 65,91 & 71,37 & 63,16 & 67,54 & 65,35 \\
D & 73,96 & 77,78 & 75,87 & 63,49 & 74,56 & 69,03 & 43,49 & 42,22 & 42,86 \\
\hline CV\%
\end{tabular}

proteínas não-lácteas pelos bezerros, em grau maior quanto menores suas idades. Noller et $a l^{14}$ (1956) encontraram valor de $51,6 \%$ para a digestibilidade de proteína da soja aos 34 dias de vida.

Os coeficientes da variação nos ensaios de digestibilidade de $2,69 \%$ para $\mathrm{MS}, 14,49 \%$ para $\mathrm{PB}$ e $10,07 \%$ para MM estiveram dentro dos limites esperados nesses tipos de experimentos. O fato de haver diferença estatística entre tratamentos dá segurança aos resultados de digestibilidade, uma vez que, segundo Gomes ${ }^{6}$ (1985), sendo as diferenças entre tratamentos consideradas significativas, nenhuma objeção pode ser levantada quanto ao baixo número de repetições e de graus de liberdade para o resíduo.

\section{CONCLUSÕES}

Nas condições do presente experimento, foi possível enumerar as conclusōes seguintes:

1) A digestibilidade da proteína láctea, em sucedâneos, foi acentuadamente mais elevada que a da proteína do concentrado protéico de soja, a julgar pelo decréscimo linear ocorrido nas digestões protéicas de sucedâneos, com substituição de até $60 \%$ de proteína láctea pela do concentrado protéico de soja.

2) O emprego de até $60 \%$ da proteína dos sucedâneos de leite como concentrado protéico de soja é viável a partir dos 30 dias de idade, desde que a quantidade de PB do sucedâneo seja acrescida visando a compensar a queda na digestão da fonte protéica nāo-láctea.

\section{SUMMARY}

Eight calves were used in a digestibility assay, to evaluate digestibilities and mineral absorption rates of four milk replacers, used as only feed sources, and varying according to the nature of their protein: (A) 100\% of digestible protein from milk, (B) $20 \%$ of Digestible Protein as Soybean Protein Concentrate, (C) $40 \%$ of Digestible Protein as Soybean Protein Concentrate and (D) $60 \%$ of Digestible Protein as Soybean Protein Concentrate. The apparent Digestibility Coefficient for Dry Matter, Crude Protein and Ash absorption were: (A) 87.63, 85.39 and 69.97\%; (B) 83.73, 79.82 and 52.54\%; (C ) 80.95, 71.37 and $65.35 \%$ and (D) $75.7,69.03$ and $42.86 \%$, respectively, with significant linear regression effect $(p<0.01),(p<0.05)$ and $(p<0.05)$. No differences among treatments were observed for diarrhea incidences.

UNITERMS: Soya protein; Calves; Milk substitutes; Digestibility.

\section{REFERÊNCIAS BIBLIOGRÁFICAS}

I-AKINYELE, I.O.; HARSHBARGER, K.E. Performance of young calves fed soybean protein replacers. Journal of Dairy Science, v.66, n.4, p.825-32, 1983.

2-ASSOCIATION OF OFFICIAL ANALYTICAL CHEMISTS, Official methods of analysis. 13.ed. Washington, AOAC, 1980. 1018p.

3-CAMPOS, O.F.; HUBER, J.T. Performance and digestion by calves from limestone added to milk replacers containing soy protein concentrate. Journal of Dairy Science, v.66, n. I I, p.2365-72, 1983.

4-COLVIN, B.M.; RAMSEY, H.A. Soy flour in milk replacers for young calves. Journal of Dairy Science, v.51, n.6, p.898-904, 1968.
5-EZEQUIEL, J.M.B.; HERLING, V.R.; ARAUJO, W.A. Digestibilidade de raçōes fornecidas a bezerros Jersey desaleitados precocemente recebendo leite de soja. Revista da Sociedade Brasileira de Zootecnia, v. 17, n.4, p.372, 1988.

6-GOMES. F.P. Curso de estatística experimental. 11 cd. Piracicaba, Nohel/ESALQ, 1985, 430p.

7-JENKINS, K.J. Pepsin and pachreatin supplementation of calf milk replacer containing soy protein. Canadian Journal of Animal Science, v.61, n.2, p.469-76, 1981.

8-MELOTTI, L; LUCCI, C.S. Determinaçăo do valor nutritivo dos capins Elefante Napier (Pennisetum pupureum) e fino (Brachiaria mutica) através de ensaio de digestibilidade (aparente) com terneiros. Boletim de Indústria Animal, v.26, n único, p.275-84, 1969

9-NATIONAL RESEARCH COUNCIL. Nutrient requirements of dairy cattle. 6.ed.rev. Washington, National Academy Press, 1988. 157p. 
ALVAREZ, J.C.; LUCCI, C.S.; MELOTTI, L. Digestibilidade (aparente) de sucedâneos do leite com bezerros. Braz. J. vet. Res. anim. Sci. São Paulo, v.33, supl., p.281285,1996

10-NATIONAL, RESEARCH COUNCIL. United-States-Canadian tables of feed composition. 3.ed.rev. Washington, National Academy Press, 1982. 69p.

11-NITSAN, Z; VOLCANI, R.; GORDIN, S.; HASDAI, A. Growth and nutrient utilization by calves fed milk replacers containing milk or soybean proteinconcentrate heated to various degrees. Journal of Dairy Science, v.54, n.9, p.1294-9. 1971

12-NITSAN, Z.; VOLCANI, R; HASDAI A.; GORDIN, S. Soybean protein substitute for milk protein in milk replacers for suckling calves. Journal of Dairy Science, v.55, n.6, p.811-21, 1972 .

13-NOLLER, C.H.; HUFFMAN, C.F.; WARD, G.M.; DUNCAN, C.W. Dried whey and lactose as supplements to a vegetable milk replacer. Journal of Dairy Science, v.39, n. 7, p. 992-7, 1956.

14-NOLLER, C.H.: WARD, G.M.; MCGILIARD, A.D.; HUFFMAN, C.F.; DUNCAN, C.W. The effect of age of the calf on the availability of nutrients in vegetable milk replacer rations. Journal of Dairy Science, v.39, n.9, p.1288$98,1956$.

15-NORNBERG, M.F.B.L.; PEIXOTO, R.R. Valor do Escol R-200 como substituto parcial de proteína do leite natural para terneiros desaleitados precocemente. Revista da Sociedade Brasileira de Zootecnia, v.17, n.1, p.49, 1988.

16-PEJIC, N ; KAY, M. Soya flour in milk replacers for young calves. Animal Production, v.28, n.3, p.420, 1979.

17-PIMENTEL, M.A.; PEIXOTO, R.R. Desaleitamento precoce de terneiros. I. Dieta líquida artificial e manejo de entabulação. Revista da Sociedade Brasileira de Zootecnia. v.12, n.4, p.637, 1983.

18-ROY, J.B. The calf. 4.ed. London, Butterworths, 1980. 442p.

19-ROY, J.B.; STOBO, I.J.F.; GANDERTON, P.; GILLIES, C.M. The nutritive value of non-milk proteins for the preruminant calf. The effect of replacement of milk protein by soybean flour or fish-protein concentrate. British Journal of Nutrition. v. 38, n.2, p.167-86, 1977

20-SILVA, A.G.; HUBER, J.T.; DE GREGORIO, R.M. Influence of substituting two types of soybean protein for milk protein on gain and utilization of milk replacers in calves. Journal of Dairy Science, v.69, n. 1, p.172-80, 1986 